\title{
The Body Image and Illogical Thoughts and Believes Comparison of Amputation Persons with Ordinary Persons
}

\author{
Ali Mohammadi Bolban Abad \\ Department of Elementary Educational Sciences, Islamic Azad University, \\ Qorveh Branch, Qorveh, Iran \\ E-mail address: Rahbord10@gmail.com
}

\begin{abstract}
This study aims to determine and compare the body image satisfaction, illogical thoughts and believes of amputation persons with ordinary persons. In this study we used the scientific comparison method. The study sample consists of all amputation people that are under the sponsored of martyr and amputee's affairs foundation and social welfare organization, and the equal or matched ordinary people with those in Qorveh. According to the limitation of persons with amputation, 25 subjects of amputation persons that was under the support of martyr and amputee's affairs foundation and social welfare organization was selected purposefully and also 25 subjects of ordinary people was chosen randomize as samples; (they) were selected as statistical sample with the cloning and homogenization method with amputation group. For measuring body image satisfaction, the 24 questions of body image satisfaction scale of Mashhad's Ferdowsi University were used (Parizade, 2012). The Cronbach's alpha coefficient of test $(\alpha=0 / 91)$ show the acceptable reliability of this scale in measuring satisfaction of body image. To assess the logical thoughts and believes; the 40 questions of logical thoughts and believes questionnaire from Jones was used that validated in Ahwaz (Abadi and Moatamedin, 2005). The final test score is 0/79 that shows the high detection strength test. For data analysis, also the Pearson's correlation coefficient, the independent t-test was used. The results of hypothesis research testing show that there is meaningful and negative relationship between body image satisfaction and illogical thoughts and believe of ordinary people with amputation persons. In other words, the increscent of body image satisfaction results are decreased their illogical believes in both groups. Also the results indicate that a meaningful difference is observed between the satisfaction of body image and illogical thoughts and believes in both groups of ordinary and amputation persons. In other words, people with amputation have a lower body image satisfaction and a higher illogical believes about themselves.
\end{abstract}

Keyword: Body Image Satisfaction; Illogical Thoughts and Believes; Amputation

\section{INTRODUCTION}

The handicap (amputation) is consists of deprivation and inappropriate condition of a person that is a result of a defect or disability, that the normal considered role of a person according to the age, sex, social and cultural conditions will be prevented from doing. In the meantime, the movement disabilities have the highest level of prevalence of disability; amputation is one of the most common kinds of disability (Devereux, 2005). 
Amputation is very different from a region than other regions in the world. The most common factors of amputation are trauma, disease and congenital malformation (Ma'somi, 2008). But in development countries or those that is under the rape of tyrant powers, amputation usually occur due to accidents or war injuries that may also cause other lateral disabilities (Behdani and Feyzi, 2009).

War and disease are two major problems of public health of the society that its heavy causalities and destructions lead to long last affections on people's body and mind. One of these issues is the quality of life that will be in danger because of less attention to the basic needs of health and rehabilitation (Behdani and Feyzi, 2009). Today, the life quality and emotional disorders of publications are referred as a framework for providing services appropriate to different aspects of life and the allocation of resources.

The importance of measuring life quality and emotional disorders are so that some know their improvement ass the most important aim in remedial intervention (Katsching at al. 2002). The proposed definitions of life quality which are useful for using in health care can be divided into five areas that include: ordinary life, happiness and satisfaction, personal goals, usefulness to society and natural capacity level. In other words, it can be known as the interface between the health status of a person on the one hand and the ability to purse the life goals on the other hand. So it seems that satisfy basic human needs and preference, play an important role in the life (Park J, 1995).

Many factors such as physical and mental health affect the life quality of people but the physical and mental changes after amputation in patients, and if then mental health and physical damages don't diagnosis early and fast, and also the essential treatment policies don't be made, it can an unpleasant, severe and visible impacts and consequences on their life quality and also their families (Bahraynian and Borhani, 2005).

Amputation in people like other chronic diseases can affect various aspects of people's life and cause many disabilities, because many of these patients suffer from medical chronic complications which lead to loss the quality of life and limit their physical activities (Kawana, 2001). These limitations are seen in many daily activities such as dressing, personal cleanliness, bathing, eating, managing the household and using the office equipment and public facilities, and also may reduce the people's confidence significantly, and affect the image of their body negatively. Body image has a multi-dimensional structure but it's often defined as a degree of satisfaction of physical appearance, size, shape and general appearance (Omidvar at al, 2003).

This image is formed from birth and grows simultaneously with the perfection of person and it changes during the life (Souto, 2002). The physical self-concept and physical selfdescriptive show the person attitudes toward body size, physical abilities and skills such as body appearance, the fat of the body, flexibility, coordination, endurance strength and etc., as a dimension of non-academic self-concept (Grant K, 1999). Body image satisfaction has a special importance, because the satisfaction of the body mass has a positive correlation with self-esteem and self-confidence (Omidvar at al, 2003). Even a change in a body image can have a large influence on a person's personality (Hargreaves DA, 2004).

So, amputation and disability cause by that reinforce their sense of vulnerability and increase their tendency to substance abuse or clinical depression and suicidal ideation rate (Desmond DM, 2007). In this regard, the results of studies about this high risk group in Iran show depression, anxiety, anger, resentment, fear, helplessness and hopelessness in these people (Afroz, 2002). Therefore, we can expect those secondary physical and psychological diseases of amputation persons and the consequences of amputation such as disorder in interpersonal relations; unemployment and loss of job, loss of family socioeconomic and 
other issues distract family from its normal position and increase their vulnerability and other family members against these mental illnesses, disorders and illogical believes (Khaghan Zade, 2005). With this knowledge that psychological disorders are results of a combination of biological, environmental and social factors, we can hardly bring up just a single reason for a disorder. Sometimes, events are lead to later cognitive distortions, and lack of experience or training may lead to incorrect or inconsistent ways of thinking (Bak and Vayshar, 1989, quote from Gordi, 2006).

Perhaps under presser conditions, their thoughts change when the persons forecast and understand impending situation. These incorrect thoughts are not just because of psychological disorders but a combination of biological, growth and environmental factors play a role in the genesis and generating disorders (Bak and Vayshar, 1989, quote from Gordi, 2006). Bak's theory about stirring disorders indicates that the first component in this kind of disorders is the presence of negative automatic thoughts. These thoughts are unusual and often put out by events not essentially the results of oriented thought. They seem that are sudden and valid for the person.

With this meaning that these thoughts are accepted like facts without any more analysis on them. Their results are led to the creation of chaos and cause more thoughts and ideas in a downward direction of disappointment (William at al, 1999, quote from Gordi, 2006). According to the presented cases, we are up to survey this problem with doing a research that is there any differences about body image satisfaction, the kinds of the thoughts and illogical believes between amputation persons and ordinary persons?

\section{THEORETICAL FOUNDATIONS}

\section{1. Ablation or Amputation}

The handicap (amputation) is consists of deprivation and inappropriate condition of a person that is a result of a defect or disability, that the normal considered role of a person according to the age, sex, social and cultural conditions will be prevented from doing. In the meantime, the movement disabilities have the highest level of prevalence of disability; amputation is one of the most common kinds of disability (Devereux, 2005). Amputation is totally a lack of existence of a part or a whole parts of body organs that are done by surgery or trauma (Hag Berg 4, 2004).

\section{1. 1. Amputation Factors}

Amputation is very different from a region than other regions in the world. The most common factors of amputation are trauma, disease and congenital malformation (Ma'somi, 2008). But in development countries or those that is under the rape of tyrant powers, amputation usually occur due to accidents or war injuries that may also cause other lateral disabilities (Ma'somi, 2008).

War and disease are two major problems of public health of the society that its heavy causalities and destructions lead to long last affections on people's body and mind, and one of the effective factors on occasion level the time course (Starting Time) and psychologicalbehavioral disorders process.

Amputees suffer from psychological-behavioral problems more and tougher than general people. Studies show that one of the four soldiers that come back from war suffers from severe psychological problems (Barnwell, 2012). 
In our country, because of the eight years war and the stresses that caused by it, psychological disorders are considered as a prevalent issue that fighters, amputees and their families suffer from it (Vafai, 2009).

One of the problems that are a result of the war is amputating veterans. After amputation, amputees physical and mental health will change, and if these psychological and physical problems don't determine and cure in time, they will cause some unpleasant effects and complications on amputees and their families and specially their children life (Bahreynian, 2004).

Amputation in amputees like other chronic illnesses can effect different aspects of these people life and cause various disabilities, because some of them involve in medical chronic complications. These limitations are seen in many daily activities such as dressing, personal cleanliness, bathing, eating, managing the household and using the office equipment and public facilities, and also may reduce the people's confidence significantly, and affect the image of their body negatively, reinforce their sense of vulnerability and increase their tendency to substance abuse or clinical depression and suicidal ideation rate (Desmond DM, 2007).

The most important factor of cutting war injury's organs (ulcerous) in Iran was traumatic (straight incident with mine and quiver) and then another more important prevalent factor is secondary infection. Beneath amputation is the most prevalent form of amputating in war ulcerous, and among all beneath amputation, amputating from under the knee is the most prevalent form. Foot amputating can happen during the war or happen after (war) by surgeon in the hospital (Shahryar, 2007).

\section{BODY IMAGE}

Body image is a multi-dimensional structure, dynamic, unstable and basically social that is a complex combination of theories, feelings and values and is firmed by formats and reflections that validate by society and transmit during the time (De Sousa, 2008). Body image means the feeling one's has about his/her physical and sexual beauty. In other words, it means that how persons see their bodies and what feeling they have about it and also how others see their bodies.

This expression (term) was used first time by Paul Schilder, an Australian neurologist and psychoanalyst in his book named "The Image and Appearance of The Human Body (1935)" (Alta, 2007). Although this term is in different majors such as Medicine, Psychology, Psychiatry, Psychoanalysis, Philosophy, Cultural studies and Feminist studies, but it hasn't fix and general meaning in all of these majors.

The human society valorized for human body beauty. But this beauty hasn't a single definition in all cultures and during the history. The self-body image is pretty a result of personal experiences, personality and various cultural and social factors like beauty definition. The person's feeling about his/her physical appearance in other's eyes and cultural ideals that live in it, formed self-body image of him/her. It's important for us to know that one's understanding about him/herself can be different from others understanding or social standards. Also, the self-body image has various kinds of physical and psychical effects on the person (Keyvan at al, 2011). 


\section{RESEARCH HISTORY}

Akarsv at al. (2012) in a study for surveying the function and quality of life and function of two groups consist of 15 persons, one sided amputating and 15 persons, two sided amputating patient's life based on the cause, amputation level and the time of using Protez, he reached these results that the physical, corporeal function and emotional score of two sided amputating group was remarkably lower than another group. But the total score of protez and body image satisfaction was same in both groups.

In the other hand, the protez satisfaction and body image don't have any relation with amputation level, but life quality and protez satisfaction will increase parallelly with using protez. Srivastar at al. (2012) in a study for surveying psychical interferences affections on amputation patients so he reached these results on 50 bedridden men about amputation that there is meaningful differences in depression level score, anxiety and the confidence before and after psychical interferences in patients.

Totally the results showed the psychology assessment and psychical interferences should be existed as amputation manager. Veterhan (2002) in a study for the effect of attending in body activities on body image in amputation patients, that was done with the participation of 24 persons of amputation people with at least 18 years old, reached these results and they shows that there is a positive relationship between body activities and body image of amputation people. Mallow at al. (2008) in a study for surveying psyche health relationship with illogical thoughts reached this result that student's high anxiety level and condition in the psychical pressure conditions is in relation with their illogical thoughts (Soltani Nejad, 2009). Hasan Khan at al. (2011) in a study for surveying amputees life quality in Mazandaran with the aim to determine the life quality of Mazandaran amputees with the descriptive study method and by accidentally choosing, and using questionnaire reached this result that just 6 percent of participating amputees in the statistic examples, have acceptable life quality that can be caused by lack of suitable remedial services and rehabilitation.

Amidi at al. (2007) in a study about the relationship between body mass and body image satisfaction, reached this result that: although there is a positive relationship between body mass and body image satisfaction, but girls appearance satisfaction score showed that only slim and tall girls satisfy from their appearance and although most of the girls have a suitable height and weight but they displeased from their appearance and wish to get longer. Even though me some of the girls were tall with suitable weight but they displeased from their self-body distribution (Fat in women).

The girls, separated from the weight and self-body mass, they don't have an appropriate body image and have a tendency to be slim under the social pressures. Gordi at al. (2006) in a study for psyche health relation with the illogical thoughts of Shahid Beheshti university students with 385 statistic samples that was chosen accidentally, reached this result that the psyche health level of samples have a straights and meaningful relation with their illogical thoughts totally, and with different kinds of others confirmation, inordinate self-expectation, reaction to failure, excitement irresponsibility, the anxious concern, avoid of making problem and failure for inverse and meaningful relationship and with the perfectionism.

\section{RESEARCH METHOD}

The aim of this study is to determine and compare body image satisfaction and thoughts kind and illogical believes of amputation persons with ordinary people. So In this study we 
used the scientific - comparison method. The study sample consists of all amputation people that are under the sponsored of martyr and amputee's affairs foundation and social welfare organization, and the equal or matched ordinary people with those in Qorveh. According to the limitation of persons with amputation, 25 subjects of amputation persons that was under the support of martyr and amputee's affairs foundation and social welfare organization was selected purposefully and also 25 subjects of ordinary people was chosen randomize as samples; (they) were selected as statistical sample with the cloning and homogenization method with amputation group. For measuring body image satisfaction, the 24 questions of body image satisfaction scale of Mashhad Ferdowsi University were used (Parizade, 2012).

The Cronbach's alpha coefficient of test $(\alpha=0 / 91)$ show the acceptable reliability of this scale in measuring satisfaction from body image. To assess the logical thoughts and believes; the 40 questions of logical thoughts and believes questionnaire from Jones was used that validated in Ahwaz (Abadi and Moatamedin, 2005). The thoughts and logical believes consist of four-dimensional 40 questions include: failure against changing, expect other confirmation, avoid of making problem and excitement irresponsibility. The rating of this 40 questions questionnaire includes 5 degrees that is $1=$ Extremely Disagree and $5=$ Extremely Agree. The high score shows the high illogical believes and low score shows the low illogical believes. The final test score is 0/79 that shows the high detection strength test. For data analysis, also the Pearson's correlation coefficient, the independent t-test was used.

\section{RESULTS}

Assumption 1: There is a meaningful relationship between body image satisfaction and illogical thought and believes of amputation persons and ordinary persons.

For surveying the relationship between body image satisfaction and illogical thoughts and believes of amputation persons with ordinary persons according to the kind of variants scale, Pearson's correlation test was used. The stated study results in Table (1) show that there is a negative and meaningful relation between the body image satisfaction level and illogical thoughts and believes of amputees and ordinary people at one percent level. In other words, increscent the body image satisfaction of amputees I both groups, decrease the illogical believes in them.

Table 1. The relationship between body image satisfaction and illogical thoughts and believes of amputation persons with ordinary people.

\begin{tabular}{|c|c|c|c|}
\hline Randomize variant & $\begin{array}{c}\text { The correlation } \\
\text { coefficient kind }\end{array}$ & $\begin{array}{c}\text { The correlation } \\
\text { coefficient }\end{array}$ & Significance level \\
\hline Independent variant & Pearson & $-0 / 565 * *$ & $0 / 000$ \\
\hline
\end{tabular}

*and ** with the meaningfully order from one percent level and five percent level

Assumption 2: There is a meaningful statistic difference between body image satisfactions in amputees with ordinary persons.

For surveying the difference between body image in the studied group (amputation persons and ordinary persons), the t-test was used. According to the stated results in Table (2), the body image comparison in relation with studied groups is described below: 
Table 2. The body image comparison based on category.

\begin{tabular}{|c|c|c|c|c|c|c|c|c|}
\hline $\begin{array}{c}\text { The Variant } \\
\text { Category }\end{array}$ & $\begin{array}{c}\text { Variant } \\
\text { levels }\end{array}$ & Abundance & Average & $\begin{array}{c}\text { Standard } \\
\text { Deviation }\end{array}$ & $\begin{array}{c}\text { Standard } \\
\text { error }\end{array}$ & $\begin{array}{c}T \\
\text { Statistic }\end{array}$ & $\begin{array}{c}\text { Freedom } \\
\text { degrees }\end{array}$ & $\begin{array}{c}\text { Meaningfully } \\
\text { level }\end{array}$ \\
\hline $\begin{array}{c}\text { Body Image } \\
\text { Satisfaction }\end{array}$ & Amputation & 25 & 72 & $4 / 35$ & $0 / 87$ & \multirow{2}{*}{$4 / 79$} & 48 & $0 / 000$ \\
\hline & Ordinary & 25 & 84 & $12 / 40$ & $2 / 48$ & & & \\
\hline
\end{tabular}

The results of Table (2) indicate that visible meaningful difference is seen in person's body image satisfaction in the both groups, amputation persons and ordinary persons that, observed t level (4/79) with freedom degrees (48) is bigger than its critical level, so we can say that there is a meaningful statistic difference between the person's body image in both amputees and ordinary people. In other words, the amputation persons have a lower body image satisfaction than ordinary people.

Assumption 3: There is meaningful statistic difference between the illogical believe of amputation persons with ordinary people.

For surveying the differences between illogical thoughts in the studied groups (amputation persons and ordinary persons), the T-test was used. According to the stated results in table (3), the comparison of the illogical believes in relation with studied groups are described below:

Table 3. The comparison of the illogical believes based on category.

\begin{tabular}{|c|c|c|c|c|c|c|c|c|}
\hline $\begin{array}{c}\text { The Variant } \\
\text { Category }\end{array}$ & $\begin{array}{c}\text { Variant } \\
\text { levels }\end{array}$ & Abundance & Average & $\begin{array}{c}\text { Standard } \\
\text { Deviation }\end{array}$ & $\begin{array}{c}\text { Standard } \\
\text { error }\end{array}$ & $\begin{array}{c}\mathrm{T} \\
\text { Statistic }\end{array}$ & $\begin{array}{c}\text { Freedom } \\
\text { degrees }\end{array}$ & $\begin{array}{c}\text { Meaningfully } \\
\text { level }\end{array}$ \\
\hline $\begin{array}{c}\text { Body Image } \\
\text { Satisfaction }\end{array}$ & Amputation & 25 & 176 & $1 / 22$ & $0 / 24$ & \multirow{2}{*}{$-293 / 84$} & 48 & $0 / 001$ \\
\hline & Ordinary & 25 & 61 & $1 / 53$ & $0 / 31$ & & & \\
\hline
\end{tabular}

The results of Table (3) indicate that visible meaningful difference is seen in person's illogical believes in the both groups, amputation persons and ordinary persons that, observed $t$ level (-293/84) with freedom degrees (48) is bigger than its critical level, so we can say that there is a meaningful statistic difference between the person's illogical believes in both amputees and ordinary people. In other words, the amputation persons have a lower illogical believes about themselves than ordinary people.

\section{DISCUSSION AND CONCLUSION}

This study aims to determine and compare the body image satisfaction, thought kinds and illogical believes of amputation persons with ordinary persons and also answering this question that is there a relationship between body image satisfaction, thought kinds and illogical believes of amputation persons with ordinary persons? The result of Pearson's correlation coefficient shows the existence of a relation between body image satisfaction and illogical thoughts and believes of amputation persons with ordinary people. 
The study results show that there is a negative and meaningful relationship between body image satisfaction and illogical thoughts and believes of amputees with ordinary persons at the one percent level. In other words, increscent the body image satisfaction, decrease their illogical believes. According to the results, it can be inferred that data from this study were matched indirectly with the results of Maloi at al. (2008) and Amidi at al. (2007) and Gordi at al. (2006) studies. Also the T-test results show the difference between body image satisfactions in amputation persons with ordinary persons. It can be said that there is a meaningful statistic difference between body image satisfaction in both amputation and ordinary people. In other words, the amputees have a lower body image satisfaction than ordinary people. According to the results, it can be inferred that this study's data were matched directly with the results of Veterhan (2002) and Amidi at al. (2007) studies. The Ttest results show that there is a meaningful difference between illogical believes of amputation persons with ordinary people. In other words, the amputation persons have a higher illogical believes than ordinary persons about themselves, so it can be inferred that this study's data were matches indirectly with the results of Maloi at al. (2008) and Gordi at al. (2006) studies. According to the relationship and the meaningful effect of mental image satisfaction on the illogical thought and believes of amputation persons, and based on this note that one of the illogical believes reasons is lake of mental health or its low level, so it's suggested that we try to decrease the depression level and illogical thoughts and believes, and increase the selfconfidence and mental health in them while we are notifying the amputees life quality and attending them in the body activities.

\section{References}

[1] Keyvan Ara A., Kamkar M., and Rismanchian B., The relationship of high weight with self-confidence, depression, life style and body self-imagination in the self-reagent women to the decrement weight center. Knowledge and study in the psychology 13(2) (2011) 121-144.

[2] Shahryar A., Body management and its relationship with social body acceptance, Women's guideline studies 4(1) (2007) 1-33.

[3] Soltan Nejad M., survey the disordered eating (habits) with the checkout body behavior on the Islamic Azad university students of Rafsanjan. Knowledge and study in the practical psychology, 14(8) (2009) 42-124.

[4] Khani H., Joharin, Simin K., Mohammad H., Ganji R \& Azad M., Mohammad S., Survey the life quality of amputated veterans in Mazandaran. The magazine of Khorasan's Medicine sciences university, course 3(1) (2011) 49-56.

[5] Amidi M., Ghefranim Fazlollah \& Hosseini R., Dissatisfaction relationship of mental body image and the body mass index in the teenagers girls. Two indexes of behavioral sciences researches, course 11(2) (2006) 59-65. 